\title{
Reviews
}

\section{Recovery from Eating Disorders: A Guide for Clinicians and Their Clients}

Greta Noordenbos

Wiley Blackwell, 2013, £29.99 (pb), 174 pp.

ISBN: 9781118469194

Eating disorders in general - and anorexia nervosa in particular - are bewildering and frightening for families, clinicians and patients alike. They are bewildering because in contrast to any other psychiatric disorder, patients often value at least some aspects of their disorder (e.g. being able to restrict their food intake, extreme exercise) and are reluctant to change. These disorders are frightening because of the often dramatic physical consequences and high medical risks involved. Patients and their families alike often feel extremely alone and isolated.

This is a unique book: it is based on more than 100 in-depth interviews with people with eating disorders conducted by the author. The book's authority derives in part from the many different voices of people with eating disorders, reflecting on different stages of their illness and illustrated by evocative quotes and in part from the wise, nuanced and straightforward commentary of its author, which gives context to these quotes.

The structure of the book follows the journey into and out of the illness, describing vividly the typical antecedents and common trajectories into an eating disorder, with classical tipping points into the disorder and the often arduous journey of turning things around towards recovery.

The lure and positives of the illness and treacherous friendship it provides is explored as much as the downside, as are the motivations for change and recovery.

The book's core focus on the lived experience of people with eating disorders will be very informative for patients and families alike, and is useful 'food for thought' even for seasoned clinicians trying to get a fresh view on how to help their patients turn things around.

Multiple helpful questionnaires and checklists are provided that can be used by patients as self-assessment tools either in a self-help or therapeutic context. Although the book is full of useful information, advice and clinical wisdom, it never lectures or tries to persuade; rather, it lets former patients speak of their journey and what was helpful. As such, this book is both hopeful and realistic.

Ulrike Schmidt, MD PhD FRCPsych, Professor of Eating Disorders, King's College London, Institute of Psychiatry, De Crespigny Park, London SE5 8AF, UK. Email: u.schmidt@iop.kcl.ac.uk

doi: $10.1192 /$ pb.bp. 113.044933

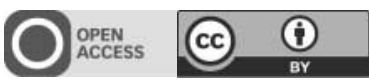

(C) 2014 The Royal College of Psychiatrists. This is an open-access article published by the Royal College of Psychiatrists and distributed under the terms of the Creative Commons Attribution License (http:// creativecommons.org/licenses/by/3.0), which permits unrestricted use, distribution, and reproduction in any medium, provided the original work is properly cited.

\section{A Clinician's Brief Guide to the Mental Capacity Act}

Nick Brindle, Tim Branton, Alison Stansfield \& Tony Zigmond RCPsych Publications, 2013, $£ 18.00$ (pb), 144 pp.

ISBN: 9781908020635

\section{Mental Capacity Legislation: Principles and Practice}

Edited by Rebecca Jacob, Michael Gunn \& Anthony Holland RCPsych Publications, 2013, E25.00 (hb), 128 pp. ISBN: 9781909726000

The Mental Capacity Act 2005 is here to stay, and increasingly psychiatrists are requested to provide an opinion on an individual's decision-making capacity by other medical practitioners or the courts. It is fair to say that the 21st-century psychiatrist needs to have an expert-level knowledge of the Act, enabling their decisions to be defended if challenged in court. There are few options available to increase one's understanding of the law in this area. The official Code of Practice $^{1}$ to the Mental Capacity Act offers little clarity, and certainly not at the level needed by a practising psychiatrist or other mental health professional, whereas Jones' Mental Capacity Act Manual ${ }^{2}$ comprises fairly dense law, and more and more psychiatrists it seems are having formal legal training. Against this background, A Clinician's Brief Guide to the Mental Capacity Act and Mental Capacity Legislation: Principles and Practice enter the fray, both broadly attending to the psychiatrist who wishes to further their understanding of the Act.

A Clinician's Brief Guide is what the Code of Practice should have been: sequentially explaining the provisions of the Act, with reference to relevant case law demonstrating how these should be applied in practice. My main criticism is that the section on 'best interests' loses this focus, concentrating on overarching principles and mechanics rather than a legal interpretation of the statutory criteria of the assessment of 'best interests'.

Mental Capacity Legislation takes a different approach, and is focused more on developing one's own clinical skills in assessing capacity as a clinician (crucial!) and interpreting 'best interests', illustrated by insightful clinical vignettes. All other provisions of the Act are covered and relevant case law mentioned, although not in as much depth as in A Clinician's Brief Guide.

Both books have excellent coverage of the Deprivation of Liberty Safeguards (DoLS) provisions, and are recommended to anyone who intends to be a mental health assessor for DoLS assessments. The case law in this area is rapidly developing, but the key developments are discussed and both achieve some clarity in this notoriously complex (and at times self-contradictory) area of legislation.

Perhaps the greatest strength of these two books is that they are both pitched for a range of audiences, leading the 
reader through the simple principles to the controversial cases, and are perhaps among the few academic books that would suit a psychiatrist at any stage in their training. Either would leave you well versed in the Act, but they are not so different as to be complimentary - one would suffice on anyone's bookshelf. If the reader wants a superior and accessible Code of Practice but does not want to tackle cold, hard law, then go for A Clinician's Brief Guide. If on the other hand you want more understanding of how to conceptualise the provisions of the Act and inform your face-to-face clinical practice, go for Mental Capacity Legislation.

1 Department for Constitutional Affairs. Mental Capacity Act 2005: Code of Practice. TSO (The Stationery Office), 2007.

2 Jones R. Mental Capacity Act Manual (5th edn). Sweet \& Maxwell, 2012.

Ben Spencer, ST5 ACF in general adult psychiatry, Department of Psychological Medicine, Institute of Psychiatry, Weston Education Centre, London, UK, email: benjamin.spencer@kcl.ac.uk

doi: $10.1192 /$ pb.bp. 113.043828

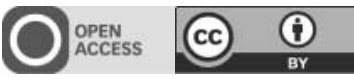

(C) 2014 The Royal College of Psychiatrists. This is an open-access article published by the Royal College of Psychiatrists and distributed under the terms of the Creative Commons Attribution License (http:// creativecommons.org/licenses/by/3.0), which permits unrestricted use, distribution, and reproduction in any medium, provided the original work is properly cited.

\section{Geriatric Psychiatry}

Mark D. Miller \& LalithKumar K. Solai

Oxford Universtiy Press USA, 2013, £35.99 (pb), 368 pp. ISBN: 9780199765782

Miller \& Solai's Geriatric Psychiatry is part of the Pittsburgh Pocket Psychiatry series. It has the look and feel of an Oxford medical handbook - its formatting and font is identical. However, the Oxford Specialist Handbooks in Psychiatry: Old Age Psychiatry ${ }^{1}$ pre-dates this text by 4 years. This raises the question of which is a better buy?
The major difference between the two books is that Geriatric Psychiatry is an American text and thus references US guidelines. Consequently, DSM is used throughout, replacing ICD criteria.

This is an ambitious book aspiring to cover the breadth of geriatric psychiatry in 16 chapters. It covers core topic areas but also dedicates chapters to additional aspects of old age psychiatry, for example the psychiatric management of chronic pain and substance use disorders. The detail dedicated to subject areas is inconsistent, with greater depth reserved for more esoteric topics, often at the expense of core subjects. One notable example is the 'brief behavioural treatment for insomnia' which was developed by the author of the sleep disorder chapter. More space is dedicated to this treatment than to psychosis in Alzheimer's disease, mood disorder, delirium and schizophrenia combined. Although some chapters are very brief, each includes a comprehensive further reading list and multiple-choice questions.

Several chapters are succinct, well written and relevant. The chapter on pharmacotherapy principles in ageing is particularly effective, utilising concise tables and clear key-fact boxes. The final chapter on psychosocial factors of health and quality of life is thought-provoking and interesting.

Ultimately, this is a handbook designed for an American audience. Personally, as a UK trainee I would choose to purchase the Oxford Specialist Handbooks in Psychiatry: Old Age Psychiatry, but Geriatric Psychiatry may be a useful adjunct.

1 Sheehan B, Karim S, Burns A. Oxford Specialist Handbooks in Psychiatry: Old Age Psychiatry. Oxford University Press, 2009.

Kathryn Milward is ST4 in old age psychiatry, Caludon Centre, Coventry, UK, email: kathrynmilward@doctors.org.uk

doi: 10.1192/pb.bp.113.043851

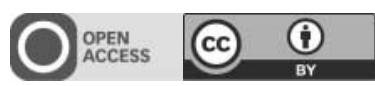

(C) 2014 The Royal College of Psychiatrists. This is an open-access article published by the Royal College of Psychiatrists and distributed under the terms of the Creative Commons Attribution License (http:// creativecommons.org/licenses/by/3.0), which permits unrestricted use, distribution, and reproduction in any medium, provided the original work is properly cited. 